\title{
The Improvement Effort for Safety A wareness Through Integrated Safety Management
}

\author{
A. Rosita \\ Universitas Widyatama \\ Bandung, Indonesia \\ L.A. Wibowo, A. Rahayu \\ Universitas Pendidikan Indonesia \\ Bandung, Indonesia \\ *masharyono@upi.edu
}

\begin{abstract}
The aim of this study is to find company suitable business process modeling by combining between the company's business processes need with SMS needs evaluate sub-system entities of the safety management system that enable to be integrated including safety support devices, Measure the ratio of individual or organizational concern to the built safety system. The value HIRA will be controlled through a data entry mechanism in the form of hazard reporting of all the functions that run the business process. HIRA values are controlled in real time through a computer system so that aspects of risk reduction and increase can be controlled transparently so that mitigation can be done earlier. Integrated safety management system is a distributed risk control effort that can be controlled and monitored jointly all the functions of the organization.
\end{abstract}

Keywords-Safety Awareness; Integrated Safety Management; Risk Management

\section{INTRODUCTION}

Safety Management System (SMS) is an effort that organized to take preventive action of potential accident hazard or failure in job operation dan continuous improvement of occupational safety and health to prevent injuries, illness and death from work [7], Systematic approach to managing safety, including organizational structure, accountability, responsibilities, policies and procedures needed [1]. Appropriate SMS is applied to any company with high, medium and low potential hazards. Hazard potential is a risk that must be anticipated earlier to reduce the risk of failure that can harm the company. Failure may occur due to procedural errors, violations and errors of the organization.

Violation is any deliberate deviation from the rules, procedures, or safe operation instructions or efficient to the factory or equipment [2]. Violations may be intentional or otherwise. The occurrence of accidents or failures today is largely due to organizational errors [3]. The degree of violation of rules and procedures is the main driver of many industrial sector accidents [4]. The current safety program works to prevent many accidents, and ultimately SMS can save companies' loss of finances loss [2].

The concept of SMS application is well known and applied to the aerospace industry, while most industries out there use the Occupational Health Safety Environment (OHSE) system approach. OHSE is a method of implementing a safety management system that prioritizes aspects of safety covering people's safety, environment, work processes and company assets [14]. While on SMS, the emphasis of safety is more emphasis on products or goods to be used as a means of human transportation in the air [1]. Safety and productivity in construction projects are positively correlated in many cases, this means that safety program investments have an impact on increased productivity [5].

In the context of organizational psychology and the perspectives of human factors, injustice, sensitivity, selfinterest and caution, and the intention to break the rules in daily activities are common predictions of potential hazards [6]. The ILO Convention (No. 161) and Recommendation (No. 171), 1985, regulate the establishment of enterpriselevel occupational health services, designed to ensure the implementation of the health surveillance system and to contribute to it implementing OSH policies [6]. Implementation of the safety system starts from the company policy declaration where the safety and health policy should be established. Such policies are implemented at the national (government) and enterprise levels.

The safety policy should be communicated effectively to all relevant parties [7]. In general, application of safety management implementation is still experiencing many obstacles. The ILO's world institutes have also developed various technical publication methods that are used as references by OSH (Occupation safety and Health). They create a set of definitions, principles, guidelines, duties, duties and rights, and technical guidance that reflects the consensus views of the ILO's tripartite constituents of its 185 members [8].

Research purposes

The development of information technology continues to grow, encouraging each company to make various managerial improvements. The simplification of business processes is essential to drive efficiency levels, simple and 
through regulatory orders, and voluntarily initiatives made by the company. Very few companies are implementing a voluntary OHSMS.

Safety system is implemented sequentially continuously, gradually while doing improvement. The sequence starts from intervention at the worksite, implementation, improvement, and final outcomes are decreasing injury rates and increasing economic value [18]. Lynda S. Robson (2007) concluded that very few companies are calculating the economic value of the implementation of the safety management system especially concerning health, environmental, and profit aspects for the company. Safety Assurance System

Safety Assurance System is a method for keeping SMSs implemented well through a continuous monitoring and measurement [19]. Measurements are made through the formulation of safety performance. While monitoring is done through safety system audit to field by analyzing data / procedure applied then compare with condition in field. The audit system also conducts an analysis of all SMS whether it is sufficient to meet the appropriate criteria in protecting the company and its employees [10].Stages of the safety assurance system are carried out through three aspects: Certification process, sustainable safety measures, and assurance support [20].

1. Certification, the safety assurace system begins with perform process of certifying OHSMS to certain institutions either government official institutions such as DGAC, FAA, EASA and others, or organizations that have certain standards such as: OHSAS, NEBOS or ISO.

2. Continue Operational Safety (COS), the role includes routine supervision functions and certification management. The purpose of this function is to assess whether the certificate holder complies with the rules of risk control or not.

3. Assurance Support, is a function to perform analysis and promotion of safety. The role of supporting the safety guarantee is to keep the Safety Assurance System program up-to-date and complete, including maintaining data collection tools (DCT), automated controls, and feedback. In the underwriting support, Resource Management is an absolute entry point.

Many companies implement overall safety systems but fail to monitor [21]. This is related to the contradiction of the company's business objectives. Safety aspect is often considered as a cost center and a source of waste. So the implementation is done just to meet the needs of regulation.

1. Priority of business interests, impact on the number potential of danger

2. Safety priorities have a decrease in productivity.

The Occupational Health and Safety Management System (OHSMS) has the goal to find the best solution by finding a middle ground for both interests. Moderate OHSMs are expected to provide effective solutions to safety related 
Assessment of risk probability

constraints.

Safety Organization

The safety action group is a type of functional organization that is in the form of a company [22]. Its formed by management with the aim as a media of communication between employees with the management in order to discuss the various issues that arise related to the implementation of safety management system. In some companies the form of safety organization can be diverse among them [22]:

3.

Actiuon Group, is the representative appointed to oversee the OHSMS road 4. Safety Patrol, some employees who are assigned in the field related to the implementation of safety

5. Emergency Response Gorup, is a group established to handle evacuation if in emergency condition

6. First Aid Officer, Is the officer who ordered to do the handling of accident victims

7. Firefighters, are group who fight the fire

8. Spill Response Group. Is a group of employees assigned to handle leakage (Spill)

\section{Hazard Identicaon Risk Assessment (HIRA)}

HIRA is a process of defining and explaining the hazard characteristics by assessing the probability characteristics and the number of occurrence frequencies as well as evaluating the severity and consequences of loss including potential adverse and injury [12]. Each potential hazard is required to evaluate and assess its potential hazard. There are two types of hazard assessment [23]:

1. Assessment probability, is assessing how often a hazard can occur, this can be judged from the experience of previous events.

2. Severy Assessment, is assessing the

hazard of severity and impact caused in the event of an accident.

HIRA is the core subject of a safety management, because this is where all the potential hazards are measured, assessed, mitigated and monitored. The safety assurance system can be assessed well if HIRA is well- maintained and properly monitored [23]. Hazard identification is carried out by a company that is represented by a special officer or Safety Committee through communication with employees in the field. The results of identification, potential hazards can be broadly divided into two, namely: potential fair hazards, and potential hazards that can cause accidents [13]. While in ICAO: ANNEX 19 (2017) assessment of potential hazards in the world of aviation is divided into two major parts:
Table 1 Probability risk [1]

\begin{tabular}{|c|l|c|}
\hline \multicolumn{2}{|c}{ Probability of occurrence } & Value \\
\hline $\begin{array}{c}\text { Qualitative } \\
\text { definition }\end{array}$ & \multicolumn{1}{|c}{ Meaning } & 5 \\
\hline Frequent & Likely to occur many times (has occurred frequently) & 4 \\
\hline Occasional & Likely to occur some times (has occurred infrequently) & 3 \\
\hline Remote & Unlikely, but possible to occur (has occurred rarely) & 2 \\
\hline Improbable & Very unlikely to occur (not known to have occurred) & 1 \\
\hline $\begin{array}{l}\text { Extremely } \\
\text { improbable }\end{array}$ & Almost inconceivable that the event will occur & . \\
\hline
\end{tabular}

Table 2 Severity Risk [1]

\begin{tabular}{|c|c|c|}
\hline \multicolumn{3}{|c|}{ Severity of occurrences } \\
\hline Aviation definition & Meaning & Value \\
\hline Catastrophic & $\begin{array}{l}\text { Equipment destroyed. } \\
\text { - Multiple deaths. }\end{array}$ & A \\
\hline Hazardous & $\begin{array}{l}\text { A large reduction in safety margins, physical distress or a } \\
\text { workload such that the operators cannot be relied upon to } \\
\text { perform their tasks accurately or completely. } \\
\text { - Serious injury. } \\
\text { - Major equipment damage. }\end{array}$ & B \\
\hline Major & $\begin{array}{l}\text { - A significant reduction in safety margins, a reduction in the } \\
\text { ability of the operators to cope with adverse operating } \\
\text { conditions as a result of increase in workload, or as a result } \\
\text { of conditions impairing their efficiency. } \\
\text {-Serious incident. } \\
\text { - Injury to persons. }\end{array}$ & c \\
\hline Minor & $\begin{array}{l}\text { Nuisance. } \\
\text { Operating limitations. } \\
\text { O Use of emergency procedures. } \\
\text { - Minor incident. }\end{array}$ & D \\
\hline Negligible & - Little consequences & E \\
\hline
\end{tabular}

Negligence and Violation

Defined as a loss of a company associated with property damage, loss of assets, employee injury, loss of life, loss of employee time, or mass destruction of company assets [23. Accidents can have a very wide impact, especially regarding customer trust. There are two things that can cause an accident that is negligence and violation. The form of negligence is not the implementation of safety management system correctly according to the scenario made by the company. The offense is a form of action or condition that violates any regulation or established procedure [24]. Safety performance should controlled on the basis of incidents or accidents recorded. The calculation can be done based on continuous monitoring of HIRA. In certain cases for highly risky companies it is necessary to establish special policies to control accidents, such as in mining, aerospace, and oil drilling areas.

\section{Methodology}

A safety management system is a method of maintaining and keep a safety system at the acceptable risk level [23]. The integration of safety systems with Enterprice Resource Planning such as SAP is possible as a means to connected monitoring hazards in every business process. To integrate two systems or more requires a comprehensive analysis of the existing business process conditions, required safety assurance, as well as safety standard parameters required. This research uses two methods: Comparative and 
Organization Business Process

The Organization Business processes are created to translate workflow in every part of the organization. Each other will be bound and need each other. The core parts of the process are finance, production, sales marketing, logistics, Quality, Human Resource, Facilities, Engineering and Safety course. In the modem organization Safety and Quality have a vital process business, because complement to each other. Quality, environment and safety have evolved in parallel in the industry, Safety is dependent on human resources, while quality is a product quality assurance operation [13]. The quality is growing rapidly due to the demands of competition, while the safety factor is growing due to regulatory demands and increasing demands on employees' guarantees. The four integration elements are currently the easiest to integrate, Quality, Safety, Environment and Health [13]. However, there may be a contradiction of interest among the three elements of that section.

Safety functions or called Department of Occupation Health Safety and Environment (OHSE) have considerable responsibility, starting from defining the creation and planning of safety programs throughout the organization, analyzing and assessing HIRA that exists throughout the department, analyzing various forms of accidents, monitoring and supervising the safety of the program, and following up any reports of potential hazards in the field. In theory, the safety management system is not only the responsibility of the department of safety, but it is the responsibility of all organizational functions

$\underset{\text { Function }}{\text { Table 3. The main work }} \underset{\text { Job Tasks }}{\text { program of a company }}$

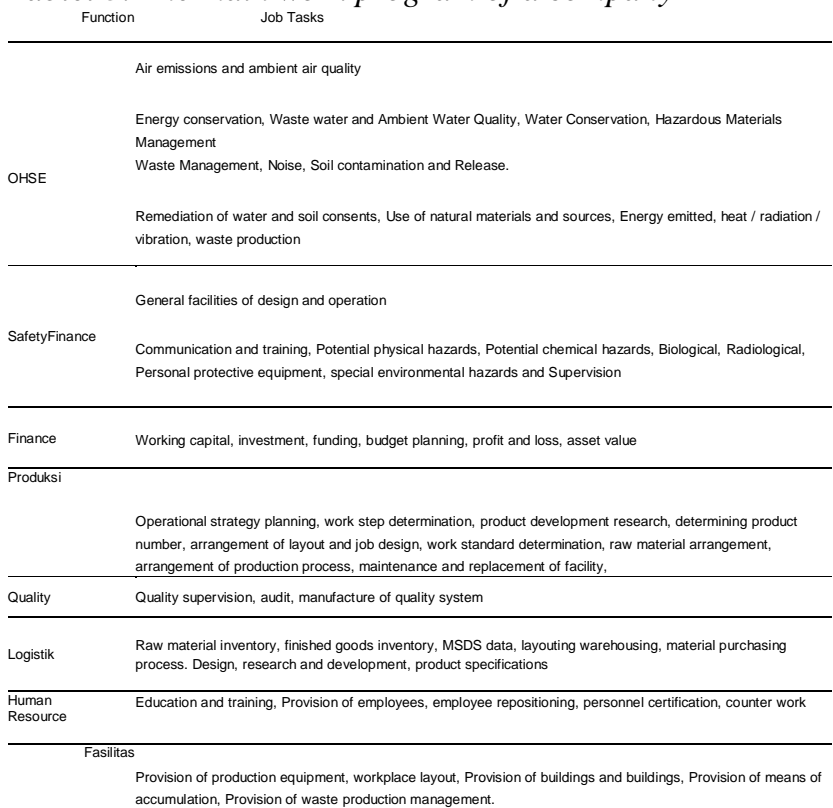

In table 3. Below are some business processes that allow to be integrated with the safety management system. The integration process should look at the scope of work of each part of the organization

The results of the analysis on each work entity in each section then the next step is to create a mapping of 
management [25]

potential hazards in each department. This needs to be done to predict and quantify the extent of hazard effects that can arise from the outset to mitigation. The first step to mitigate is to conduct hazard identification risk assessments in all areas, following the initialisation of some dominant HIRAs:

\section{Table 4. HIRA}

\begin{tabular}{|c|c|c|c|}
\hline DEPT & HIRA & 言 & MITIGATION \\
\hline & $\begin{array}{l}\text { imitations of funds for the purchase of } \\
\text { PPE (Personal Protection Equipment): }\end{array}$ & $4 \mathrm{C}$ & $\begin{array}{l}\text { Planning PPE procurement planning } \\
\text { (Personal Protective Equipment) }\end{array}$ \\
\hline Finance & $\begin{array}{l}\text { Non-production budget is small } \\
\text { compared to production cost }\end{array}$ & $4 \quad D$ & $\begin{array}{l}\text { Create a budget planning for non-production } \\
\text { costs to be mutually agreed upon }\end{array}$ \\
\hline \multirow{3}{*}{ Logistic } & Delay in procurement & $2 \mathrm{D}$ & Make planning for procurement in 1 year \\
\hline & $\begin{array}{l}\text { Occurs material / raw material or } \\
\text { finished product dead stock }\end{array}$ & $3 \mathrm{D}$ & $\begin{array}{l}\text { Create an auction program for dead stock } \\
\text { items }\end{array}$ \\
\hline & $\begin{array}{l}\text { Material / product damage due to storage is too } \\
\text { long }\end{array}$ & $4 \mathrm{C}$ & $\begin{array}{l}\text { Create system and storage procedures for specific } \\
\text { products with reference to certain standards }\end{array}$ \\
\hline \multirow{3}{*}{$\begin{array}{c}\text { Human } \\
\text { Resource }\end{array}$} & $\begin{array}{l}\text { Human capability skill does not } \\
\text { increase as targeted. }\end{array}$ & $2 D$ & $\begin{array}{l}\text { Create Reward and punishment for } \\
\text { outstanding employees }\end{array}$ \\
\hline & $\begin{array}{l}\text { Often Occurs Resign Employees in engineering } \\
\text { areas with certain skills } \\
\text { Difficulty in finding employees who are waiting for } \\
\text { a resign or retired central production area }\end{array}$ & $4 \mathrm{C}$ & Create a reward \& Funnisment Program \\
\hline & & & Creating an Outsourcing Program for a particular job \\
\hline \multirow{3}{*}{ Fascilities } & $\begin{array}{l}\text { Damage to building facilities due to } \\
\text { earthquake / fire }\end{array}$ & $2 \mathrm{D}$ & $\begin{array}{l}\text { Building insurance programs and certain } \\
\text { machines. }\end{array}$ \\
\hline & $\begin{array}{l}\text { The working room temperature does not meet the } \\
\text { required standards }\end{array}$ & $e_{2} \quad c$ & Use of air conditioner \\
\hline & $\begin{array}{l}\text { There is a rapid change of production } \\
\text { method so that it in secessary to } \\
\text { replace the production maachine }\end{array}$ & $4 \mathrm{C}$ & $\begin{array}{l}\text { Sub contracts some of the production } \\
\text { process to another place within a certain } \\
\text { period of time }\end{array}$ \\
\hline \multirow{2}{*}{ Production } & Product failure created & $2 \mathrm{D}$ & Enactment of reward Punishment \\
\hline & Delays in delivery & $4 \mathrm{C}$ & Reward And Punishment \\
\hline Quality & $\begin{array}{l}\text { The production process is not in accordance with } \\
\text { the existing quality }\end{array}$ & $2 \quad D$ & Training of QMS Production personnel \\
\hline Engineering & Design errors & $2 \mathrm{c}$ & reate a temporary red line image for quick eeds \\
\hline OHSE & $\begin{array}{l}\text { The safety guarantee system is not } \\
\text { achieved }\end{array}$ & $2 \mathrm{C}$ & $\begin{array}{l}\text { Regular meeting of management, Induction } \\
\text { routine, and training }\end{array}$ \\
\hline
\end{tabular}

Hazard Identification Risk Assessment (HIRA) specified in each section, recorded and managed by the OHSE function. The analysis is carried out in conjunction with the corresponding function in which the hazard is found. HIRA with acceptable Risk is monitored. The HIRA index value may change at any time in the event of a disruption to the business process flow. The non-acceptable RIRI Index, the work may be temporarily suspended for mitigation. Human error is a frequent violation in a work cycle, its form can be violation or work errors. Mistakes and human violations in work can lead to incidents or accidents or even fatalities. The occurrence of hazard reports is an anticipation of early risk control

However, control and analysis of variant HIRA will, of course, make it difficult for OHSE officers due to the limited personnel in the safety dept. Thousands of HIRA must consistently be monitored and updated by the OHSE function through parameter input in the form of hazard reporting from various department functions. To help facilitate analysis, HIRA needs to be designed in such a way that its data is easy to monitor and update and monitor simultaneously. Three main prerequisites in data
1. Recorded and well documented and error-free

2. Monitored continuously so HIRA has always update data

3. Accessible anytime and from anywhere

4. The data can be used as a reference by other departments so that decisions can be taken immediately.

Business Process Integration

Based on these requirements management system integration needs to be done. Integration includes all the functions of existing systems within the body of the organization based on information technology used in the company. Every business process run by the company is designed by listing the elements of HIRA in each risk analysis. The HIRA entity in every business process will be an input parameter for the safety department in order to analyze all hazard mitigation processes in all areas.

Similarly, the reporting of potential hazards, in the safety management system, the mechanism is to defect all potential hazards that are reported online and report results captured systematically by a computer-based integrated safety management system. The reporting of the potential hazards created in the safety management system will automate the associated HIRA list into high light on-screen integrated security management system applications. This HIRA marking automation inside the system will allow the OHSE function to control HIRA in fast relative time with the result of an "accepted" or "not accepted" value analysis.

Integration Safety Management System

Integration of health and safety management system is an effort to combine various modules of enterprise computer application system that has been owned by the company with the addition of plug in safety management. In the company of many ERP programs that have been successfully applied but the new system is formed only for business purposes. Additional modules need to be designed as a means of facilitating the safety management system modules that can be accessed from different departments through the tools used in each section. The basic idea is that each system module used has an interconnection to the Safety information system. Interconnection has functions:

a) Online defining HIRA

b) Online a hazard reporting

Making of HIRA online through the application module will greatly facilitate the operator because without having to get out of the application program, the system is able to immediately define HIRA without having to get out of the application routine. HIRA or Hazard Report that has been created will enter into the next

Safety Information System database, in this system each HIRA is grouped into several subgroups of monitoring modules, namely: financial HIRA monitoring, training, 
MCU (Medical Check-Up), PPE (Personal Protective Equipment), Environment, and compliance. Each submodule is connected with Safety Control System connected wirelessly. Safety Control System is a device that is installed in various hardware in the company such as: machining, Forklift, Crane, Digital Tools Equipment, and Fire Protection System. The function of the Safety Control system is to provide a warning signal either in the form of a light, bell, or disable the device centrally when the monitoring system in the safety information system changes the HIRA from "Accepted" to "not Accepted" status. With an early warning system in the form of light signals, bell sounds or on/off systems of certain devices are encouraged to provide early warning signals to field officers about the dangers.

\section{CONCLUSIONS AND RECOMMENDATIONS}

From the results of the discussion on integrated safety management system can be obtained the following conclusions:

1. That this system can be developed and applied properly and correctly if the development of this system is based on strong commitment of top management level in efforts to build safety culture in the company.

2. In this system, the function of finance becomes a central function, in which every issue related to the reporting of potential hazards will largely lead to the financial function as central financing to mitigate various problems.

Safety awareness at the operational level will be formed automatically through the wireless safety control system because of the system, early warning will be monitored and read directly on every device that is operated.

\section{REFERENCES}

[1] ANNEX 19. Second Edition Juli 2012 : Safety Management System, INTERNATIONAL CIVIL AVIATION ORGANIZATION A999 Robert- Bourassa Boulevard, Montreal, Quebec, Canada H3C 5H7

[2] Improving with Safety Procedures Reducing Industrial Violations, 1995, Human Factors in Reliability Group, , ISBN 0717609707

[3] Human factors that lead to non-compliance with standard operating procedures , 2012, Simon Bates \& Justin Holroyd,The Health and Safety Laboratory, Harpur Hill Buxton Derbyshire SK17 9JN

[4] Understanding the determinants of safety-related rule violations, 2015, Dipl. - Psych. Ananda von der Heyde, Universitat DuisburgEssen

[5] Evaluation of Safety, Quality and Productivity in Construction,2015, M A Usmen and M Vilnitis IOP Conference Series: Materials Science and Engineering. 96012061

[6] Counterproductive Work Behaviour in a Simulated Production Context: An Exploratory Study with Personality Traits As Predictors of Safety-Related

Rule Violations,2015, Ananda von der Heyde1*, Julia Miebach1 and Annette Kluge2, Duisburg- Essen, Department of Engineering, Business and Organizational Psychology, Lotharstr 65, D- 47057 Duisburg, Germany.

[7] Fundamental Principles of Occupational Health and Safety, Second Edition, 2008 , Benjamin O. Alli, International Labour Office-Geneva
[8] Safety and health in the use of machinery, ISBN 978-92-2-127725-5 ILO, Geneva

[9] The effectiveness of occupational health and safety managemen system interventions: A systematic review, 2007, Lynda S. Robson, Institute for Work and Health, 481 University Ave., Ste. 800, Toronto, Canada M5G 2E9

[10] Safety climate, safety management practice andsafety performance in offshore environments, 2003,Kathryn Mearns, Rhona Flin Industrial Psychology Group, Aberdeen, Scotland AB24 2UB, UK

[11] Hazard Identification and Risk Assessment in Foundry M.SaravanaKumar1, Dr.P.SenthilKumar2 1(Industrial Safety Engineering, K.S.R, College of Engineering / Anna University, Chennai, India), Department of Mechanical Engineering, K.S.R College of Engineering/Anna University, Chennai, India)

[12] Hazard Identification, Risk Assessment and Risk Control in Foundry,2015, SheikAllavudeen.S1, Sankar.S.P2 1 (Industrial Safety Engineering, K.S.R, College of Engineering / Anna University, Chennai, India) 2 (Department of Mechanical Engineering, K.S.R. College of Engineering/Anna University, Chennai, India)

[13] Analysis on integrated management of the quality, environment and safety on the industrial projects, 2015 J. G. Sanz-Calcedoa,*, A.G. Gonzaleza, O. Lopeza, D.R. Salgadob, I. Camberob, J.M. Herrerab, The Manufacturing Engineering Society International Conference, MESIC 2015

[14] The effectiveness of occupational health and safety management system interventions: A systematic review, 2017, Lynda S.Robson, Institute for Work and Health, 481 University Ave., Ste. 800, Toronto, ON, Canada M5G 2E9

[15] Risk Management Safeguarding Company Asset, 2007,Immanuel Fragniere \& George Sullivan, www.coursielt.com

[16] Managing Strategic Contradictions: A Top Management Model for Managing Innovation Streams,2005, Wendy K. Smith, Michael L. Tushman, Harvard Business School, Harvard University, Morgan Hall, Soldiers Field Road, Boston, Massachusetts 02163.

[17] Maintenance and management of civil infrastructure based on condition, safety, optimization, and life-cycle cost, 2007, Dan M. Frangopol, Department of Civil and Environmental Engineering , Center for Advanced Technology for Large Structural Systems, 117 ATLSS Drive, Imbt Labs, Lehigh University, Bethlehem, PA, 180154729, USA

[18] Organizational safety: Which management practices are most effective in reducing employee injury rates?, 2002 Alison G. Vredenburgh, Vredenburgh and Associates, Inc., PMB 353, 2588 Real, Suite F, Carlsbad, CA 92008, USA

[19] Application and validation of the TTI based chill chain management system SMAS (Safety Monitoring and Assurance System) on shelf life optimization of vacuum packed chilled tuna, 2008, Theofania Tsironi, National Technical University of Athens, School of Chemical Engineering, Laboratory of Food Chemistry and Technology, 5, Iroon Polytechniou, Zografou 15780, Athens, Greece

[20] Verification, validation, and certification of modeling and simulation applications, 2003,Osman Balci, New Orleans, Louisiana

[21] Occupational injuri: Risk, prevention, and intervention, 2004, AnneMarie Feyer, National Centre of Occupational and Environmental Reasearch, New Zealand

[22] Reducing violence in licensed venues through community safety action projects: the Queensland experience,1998, Marg Hauritz, Contemporary Drug Problems, vol. 25, 3: pp. 511-551.

[23] Hazard Identification Risk Assessment,1997, Geoff Well, Institute of Chemical Engineer, David Building, 165-189 Rail Way Terrace,Rugby, Warwickshire,CV21 3HQ,UK

[24] Towing Vessel Safety: Analysis of Congressional and Coast Guard Investigative Response to Operator Involvement in Casualties Where a Presumption of Negligence Exist,1994, Paul J. Cormier, University of Rhode Island 